\title{
The relationship between serum antioxidant vitamins, magnesium levels, and clinical parameters in patients with primary fibromyalgia syndrome
}

\author{
Sukran Tastan Sakarya • Yesim Akyol • \\ Abdulkerim Bedir • Ferhan Canturk
}

Received: 20 May 2010 /Revised: 27 December 2010 / Accepted: 17 January 2011 / Published online: 24 February 2011

(C) The Author(s) 2011. This article is published with open access at Springerlink.com

\begin{abstract}
We proposed to assess serum antioxidant vitamins and magnesium $(\mathrm{Mg})$ levels in patients with fibromyalgia (FM) in comparison to healthy controls. Additionally, the association between the serum antioxidant vitamins, magnesium levels, and clinical parameters in FM patients was also investigated. Forty female patients, aged between 30 and 50 years, were diagnosed with FM according to ACR-1990 criteria, and 40 healthy controls were included in the present study. Socio-demographic characteristics of participants, accompanying symptoms, and number of tender points (TP) of the patients were recorded. The intensity of pain was measured using the visual analogue scale (VAS). The functional status and depression levels were evaluated with Fibromyalgia Impact Questionnaire (FIQ) and Beck Depression Inventory (BDI), respectively. Serum vitamins A, C, and $\mathrm{E}$ and $\mathrm{Mg}$ levels were measured. There were no significant differences in the levels of vitamins $\mathrm{A}, \mathrm{C}$, and $\mathrm{E}$ and $\mathrm{Mg}$ between control subjects and patients with fibromyalgia $(p>0.05)$. In addition, no statistically significant correlations were found between mean levels of serum vitamins A, C, and $\mathrm{E}$, and $\mathrm{Mg}$ and number of TP, scores of VAS, FIQ, and BDI in patients with FM $(p>0.05)$. According to the results of this study, it was asserted that other complex mechanism may play an important role in the pathophysiology of FM without plasma antioxidant vitamins and Mg levels.
\end{abstract}

\section{S. T. Sakarya $\cdot$ Y. Akyol $(\bowtie) \cdot$ F. Canturk}

Department of Physical Medicine and Rehabilitation,

Medical Faculty, Ondokuz Mayis University,

Samsun, Turkey

e-mail: yesimakyol@yahoo.com

\section{A. Bedir}

Department of Biochemistry, Medical Faculty,

Ondokuz Mayis University,

Samsun, Turkey
Keywords Antioxidant vitamins · Fibromyalgia . Magnesium · Oxidative stress

\section{Introduction}

Reactive oxygen species (ROS) are highly reactive chemical species with an unpaired electron and formed by catalyzing transition metals like iron, copper, or manganese [1]. ROS are formed in oxidative processes that normally occur at relatively low levels in all cells and tissues. Under normal conditions, the concentrations of ROS are kept under strict control by the activity of a complex defense system including enzymes and nonenzymatic species. In contrast, high doses and/or inadequate removal ROS results in oxidative stress, which may cause severe metabolic malfunctions and damage to biological macromolecules $[2,3]$. In recent years, a great number of studies have investigated the possible role of oxidative stress in the etiopathogenesis of various rheumatological disease including rheumatoid arthritis, ankylosing spondylitis, and chronic fatigue syndrome [4-6].

Fibromyalgia (FM) is rheumatic disorder characterized by musculoskeletal pain, stiffness, and tenderness of specific anatomic sites [7]. The etiology of FM is still unknown and also it is associated with many factors and predictors $[8,9]$. Oxidative stress and/or an imbalance of trace element status may play an important role in the pathophysiology of FM [10-13].

Vitamins $\mathrm{A}, \mathrm{E}$, and $\mathrm{C}$ are known to be a powerful nonenzymatic antioxidant $[14,15]$. Vitamins $\mathrm{A}$ and $\mathrm{E}$ are essential fat-soluble vitamins. They are the major chainbreaking antioxidants in body tissues and are considered the first line defense against lipid peroxidation, protecting cell 
membranes at an early stage through free radical-quenching activity [16-18]. Vitamin $\mathrm{C}$ is the major water-soluble vitamin. It, as well as being a free radical scavenger, also transforms vitamin E to its active form [19]. Magnesium $(\mathrm{Mg})$ is a trace element, which plays a considerable role in ATP synthesis, and it is important for adequate muscle metabolism [20]. In recent years, serum $\mathrm{Mg}$ levels have been researched to reveal etiopathogenesis of patients with FM [21, 22].

In literature, there have been few studies that investigate the role of antioxidant vitamins and $\mathrm{Mg}$ in the etiopathogenesis of FM, and their results are contradictory [21-24]. We proposed to assess serum antioxidant vitamins and $\mathrm{Mg}$ levels in patients with FM in comparison to healthy controls. The association between the serum antioxidant vitamins, Mg levels, and clinical parameters in FM patients was also investigated.

\section{Materials and methods}

Forty $(n=40)$ premenopausal women who met the 1990 American College of Rheumatology (ACR) criteria for the diagnosis of FM [25] were enrolled in the study. Forty $(n=40)$ age, sex, geographic location matched demographically similar healthy premenopausal women were selected as controls. Informed consent was obtained from all subjects, and the study protocol was approved by the local ethics committee. Routine blood tests, sedimentation rate, liver and kidney blood tests, thyroid hormone concentration, and sex hormone profiles of the patients and controls were evaluated. The criteria for exclusion were severe chronic diseases (e.g., chronic renal/liver failure, hepatitis), other rheumatic diseases, severe neuropsychiatric, endocrinologic disorders (e.g., diabetes mellitus, hypo, or hyperthyroidism), painful or disabling medical conditions, neuropathic pain disease, and undesired habits (e.g., smoking, alcohol, etc.). Neither patients nor controls were using any medicine that effects the serum antioxidant vitamins and $\mathrm{Mg}$ levels and statin. None of the patients was under the treatment of antidepressants and analgesics and were only included if they had stopped using them at least 4 weeks before study.

The demographic features [age, height, body weight, body mass index (BMI), duration of disease] and accompanying symptoms [fatigue, headache, dyspnea, pollakiuria, morning stiffness (generalized stiffness of the muscles and joints after waking up in the morning especially in the hands, arms, legs, and feet lasting for $45 \mathrm{~min}$ or longer), sleep disorders, anxiety, dysmenorrhea, Raynaud's-like symptoms, and irritable bowel syndrome] of the patients were documented. The patients were examined in terms of widespread chronic pain, number of tender points (TP), functional capacity, and depression level. Severity of pain was evaluated using $10 \mathrm{~cm}$ visual analogue scale (VAS). Higher scores of VAS indicate more severe symptoms [26]. TP defined by ACR were determined by applying a $4-\mathrm{kg}$ pressure with the thumb on specific body points and the number of TP recorded. Tender point examination was carried out by the exertion of a uniform amount of manual finger pressure, until fingernail bed blanches. Functional capacity in daily living activities was evaluated by Turkish version of fibromyalgia impact questionnaire (FIQ) [27]. Depression rate was assessed by Beck Depression Inventory (BDI).The test consists of 21 questions scaled in a Likert format. The higher score shows increased depression of subjects [28]. The score over 17 was accepted to be a sign of depression.

For laboratory investigations, venous blood was taken from the cubital vein into plain and anticoagulation tubes containing sodium EDTA and protected against light, after an overnight fast and with all morning medication omitted. After serum and plasma samples were separated by centrifugation at $1,500 \times \mathrm{g}$ for $10 \mathrm{~min}$ at $+4^{\circ} \mathrm{C}$, the serum samples were used for immediate $\mathrm{Mg}$ analysis, while the plasma samples were stored in a freezer $\left(-70^{\circ} \mathrm{C}\right)$ until the time of vitamin assay analysis. Mg levels were measured with colorimetric method (Magon/Xylidyl blue) by Roche Modular equipment. Plasma vitamins $\mathrm{A}, \mathrm{E}$, and $\mathrm{C}$ levels were measured with High Performance Liquid Chromatography (HPLC) system (Agilent Technologies, Waldbronn, Germany) using the commercial kits (Chromsytems Instruments and Chemicals $\mathrm{GmbH}$, München, Germany).

\section{Statistical analyses}

Statistical Package for Social Sciences (SPSS Inc., Chicago, IL, USA) software, version 11.0 for Windows, was used for all statistical analyses. Normality analyses were made with the Kolmogorov-Smirnov test. Data showing a normal distribution were expressed with mean value \pm standard deviation. To test for statistical differences between two groups, Student's $t$ tests were used. For correlation between results, the Pearson's correlation coefficient was performed. The sociodemographical characteristics of the groups were evaluated by chi-square test. $p$ values less than 0.05 were considered statistically significant.

\section{Results}

Demographic and clinical characteristics of patients with FM and controls are shown in Table 1. Demographic characteristics were statistically similar in groups $(p>0.05)$. TP number, VAS (pain) score, BDI score, and FIQ score were significantly $(p<0.001)$ higher in patients with FM than controls. The most frequently encountered symptoms 
Table 1 Demographic, clinical characteristics, laboratory measurements, and signs and symptoms of patients with fibromyalgia and control $p$ value is significant when $<0.05$

$B M I$ body mass index, FIQ Fibromyalgia Impact Questionnaire, FSH follicle-stimulating hormone, $V A S$ visual analogue scale, $B D I$ Beck Depression Inventory, $L H$ Luteinising hormone, TSH thyroid-stimulating hormone, ST3 free thyroxine, ST4 free triiodothyronine, $E 2$ estradiol, mean $\pm S D$ mean \pm standard deviation

\begin{tabular}{|c|c|c|c|c|}
\hline Characteristics & $\begin{array}{l}\text { Fibromyalgia }(n=40) \\
\text { mean } \pm \text { SD }\end{array}$ & $\begin{array}{l}\text { Control }(n=40) \\
\text { mean } \pm \text { SD }\end{array}$ & $p$ value & $\begin{array}{l}\text { Frequency } \\
(n, \%)\end{array}$ \\
\hline \multicolumn{5}{|l|}{ Demographic characteristics } \\
\hline Age (years) & $33.61 \pm 7.55$ & $31.67 \pm 7.03$ & 0.134 & \\
\hline Height $(\mathrm{cm})$ & $161.9 \pm 5.30$ & $163.2 \pm 6.09$ & 0.398 & \\
\hline Body weight (kg) & $61.4 \pm 4.91$ & $60.6 \pm 6.06$ & 0.554 & \\
\hline BMI $\left(\mathrm{kg} / \mathrm{m}^{2}\right)$ & $23.42 \pm 1.58$ & $22.79 \pm 1.59$ & 0.076 & \\
\hline \multicolumn{5}{|l|}{ Clinical characteristics } \\
\hline Tender point number & $13.95 \pm 1.75$ & $1.68 \pm 1.82$ & 0.001 & \\
\hline Duration of disease (years) & $4.25 \pm 3.11$ & - & - & \\
\hline VAS pain score $(\mathrm{cm})$ & $8.00 \pm 1.48$ & $0.35 \pm 0.77$ & 0.001 & \\
\hline FIQ score & $61.32 \pm 9.23$ & $4.94 \pm 4.11$ & 0.001 & \\
\hline BDI score & $11.23 \pm 4.87$ & $2.10 \pm 2.48$ & 0.001 & \\
\hline \multicolumn{5}{|l|}{ Laboratory measurements } \\
\hline FT4 (ng/mL) & $0.99 \pm 0.14$ & $1.08 \pm 0.16$ & 0.078 & \\
\hline FT3 (pg/mL) & $2.65 \pm 0.44$ & $2.83 \pm 0.36$ & 0.063 & \\
\hline $\mathrm{TSH}(\mu \mathrm{IU} / \mathrm{mL})$ & $1.62 \pm 0.98$ & $1.66 \pm 0.94$ & 0.826 & \\
\hline $\mathrm{FSH}(\mathrm{mU} / \mathrm{ml})$ & $8.14 \pm 9.52$ & $9.44 \pm 18.99$ & 0.711 & \\
\hline LH (m IU/mL) & $5.63 \pm 4.23$ & $6.27 \pm 6.65$ & 0.620 & \\
\hline $\mathrm{E} 2(\mathrm{pg} / \mathrm{mL})$ & $78.55 \pm 53.69$ & $103.23 \pm 84.13$ & 0.108 & \\
\hline Vitamin A (mmol/L) & $1.46 \pm 0.47$ & $1.25 \pm 0.26$ & 0.119 & \\
\hline Vitamin C (mmol/L) & $3.69 \pm 2.20$ & $3.70 \pm 2.33$ & 0.974 & \\
\hline Vitamin E (mmol/L) & $24.39 \pm 5.25$ & $21.98 \pm 5.48$ & 0.072 & \\
\hline Magnesium (mmol/L) & $0.87 \pm 0.07$ & $0.87 \pm 0.08$ & 0.977 & \\
\hline \multicolumn{5}{|l|}{ Signs and symptoms } \\
\hline Fatigue & & & & $40(100)$ \\
\hline Anxiety & & & & $38(95)$ \\
\hline Sleep disorders & & & & $37(92.5)$ \\
\hline Headache & & & & $37(92.5)$ \\
\hline Morning stiffness & & & & $33(82.5)$ \\
\hline Irritable bowel syndrome & & & & $27(67.5)$ \\
\hline Dyspnea & & & & $24(60)$ \\
\hline Dysmenorrhea & & & & $21(52.5)$ \\
\hline Pollakiuria & & & & $13(32.5)$ \\
\hline Raynaud's-like symptoms & & & & $8(20)$ \\
\hline
\end{tabular}

accompanying patients with FM were fatigue (100\%) and anxiety (95\%), as shown in Table 1.

The mean concentrations of thyroid hormones (thyroidstimulating hormone-TSH, free triiodothyronine-FT3, free thyroxine-FT4), sex hormones (follicle-stimulating hormone-FSH, Luteinising hormone-LH, estradiol$\mathrm{E} 2$ ), vitamins $\mathrm{A}, \mathrm{C}$, and $\mathrm{E}$ and $\mathrm{Mg}$ in plasma of patients with FM and controls are shown in Table 1. There were no significant differences between groups according to TSH, FT3, FT4, FSH, LH, and E2 $(p>0.05)$. The mean values of vitamins $\mathrm{A}, \mathrm{C}$, and $\mathrm{E}$ in patients and controls were 1.46 and $1.25,3.69$, and $3.70,24.39$, and $21.98 \mathrm{mmol} / \mathrm{L}$, respectively. Patients and controls both had a mean $\mathrm{Mg}$ level of $0,87 \mathrm{mmol} /$ L. There were no significant differences in the levels of vitamins $\mathrm{A}, \mathrm{C}$, and $\mathrm{E}$ and $\mathrm{Mg}$ between control subjects and patients with FM $(p>0.05)$. In addition, no statistically significant correlations were found between mean levels of serum vitamins $\mathrm{A}, \mathrm{C}$, and $\mathrm{E}$ and $\mathrm{Mg}$ and number of $\mathrm{TP}$, scores of VAS (pain), FIQ, and BDI in patients with FM $(p>0.05$; Table 2).

\section{Discussion}

The etiology and pathogenesis of FM are not clearly understood. Recent studies have demonstrated that oxidative stress and serum trace elements may have a role in the pathophysiology of FM [10, 11]. For the purpose to support the etiopathogenesis of FM, we assessed serum antioxidant vitamins, $\mathrm{Mg}$ trace element levels in patients with FM in 
Table 2 Correlation between serum antioxidant vitamins, magnesium levels and clinical findings in patients with fibromyalgia

\begin{tabular}{lrrrr}
\hline & Vitamin A & Vitamin C & Vitamin E & Magnesium \\
\hline \multicolumn{2}{l}{ Tender point number } & & & \\
$r$ & -0.110 & -0.170 & -0.150 & 0.121 \\
$p$ & 0.499 & 0.294 & 0.357 & 0.457 \\
\multicolumn{2}{l}{$\begin{array}{l}\text { VAS pain } \\
\text { score }(\mathrm{cm})\end{array}$} & & & \\
$r$ & -0.195 & 0.081 & -0.311 & 0.165 \\
$p$ & 0.228 & 0.621 & 0.051 & 0.309 \\
FIQ score & & & & \\
$r$ & -0.083 & -0.115 & -0.171 & 0.014 \\
$p$ & 0.611 & 0.481 & 0.291 & 0.934 \\
BDI score & & & \\
$r$ & 0.177 & -0.098 & -0.246 & -0.032 \\
$p$ & 0.276 & 0.548 & 0.126 & 0.844 \\
\hline
\end{tabular}

$p$ value is significant when $<0.05$

$V A S$ Visual Analogue Scale, FIQ Fibromyalgia Impact Questionnaire, $r$ Pearson's correlation coefficient, $B D I$ Beck Depression Inventory

comparison to healthy controls. Additionally, the association between the serum antioxidant vitamins, $\mathrm{Mg}$ levels, and clinical parameters in FM patients was also investigated. As a result, there were no significant differences in the levels of vitamins $\mathrm{A}, \mathrm{C}$, and $\mathrm{E}$ and $\mathrm{Mg}$ between control subjects and patients with FM. In addition, no correlations were found between levels of serum vitamins $\mathrm{A}, \mathrm{C}$, and $\mathrm{E}$ and $\mathrm{Mg}$ and number of TP, severity of pain, functional capacity, and depression in patients with FM.

The increase in toxic ROS and decrease in antioxidant defense mechanism are defined as oxidative stress and contribute to local tissue injury, organ dysfunction, and many disorders including inflammation, carcinogenesis, atherosclerosis, and neurodegenerative diseases [3]. The role of free radical-mediated oxidative damage was investigated in the etiopathogenesis of FM. Fassbenger and Wegner [29] reported that muscle tender points in FM result from local hypoxia. Lund et al. [30] indicated abnormal oxygen pressure at the muscle surface above trigger points. Another study showed microcirculatory disturbances in tender points [31]. These studies lead to the importance on oxidative stress as a basic pathologic process in FM.

In literature, there are studies on enyzmatic antioxidant capacity of plasma (superoxide dismutase, catalase, glutathione peroxidase, adenosine deaminase) in patients with FM $[10,32,33]$. These study findings may support the hypothesis of FM as an oxidative disorder. Vitamins A, E, and C are known to be a powerful non-enzymatic antioxidant $[14,15]$. To our knowledge, there are two studies on vitamins $\mathrm{A}$ and $\mathrm{E}$ concentrations and one publication on vitamin $\mathrm{C}$ concentration in blood of patients with FM [23, 24]. Eisinger et al. [24] measured plasma vitamins $\mathrm{A}$ and $\mathrm{E}$ concentrations in 28 patients with FM and 20 age-matched controls, and they found that there were no statistically significant changes in any of the vitamin concentrations in the patients. In contrast, Akkus et al. [23] showed that vitamins A and E levels in 30 female patients with FM were lower than in 30 age- and sexmatched controls and plasma vitamin $\mathrm{C}$ concentrations of patients did not change. They reported that plasma vitamins $\mathrm{A}$ and $\mathrm{E}$ concentrations in the patients may be used as a result of their role action on radical inhibition. In the present study, there were no significant differences in the levels of plasma vitamins $\mathrm{A}, \mathrm{C}$, and $\mathrm{E}$ between control subjects and patients with fibromyalgia. The study population of the study of Akkus et al. is similar to that of our study, but their results had considerable difference. They used spectrophotometric analysis, but we analyzed our data with HPLC. Since we did not use the same method, the results cannot be comparable. There are little and paradoxical data, so more clinical trials are needed to explore the issue.

The role of $\mathrm{Mg}$ deficiency in patients with $\mathrm{FM}$ is controversial. Similar to the current study in past years, Prescott et al. [34] and Rosborg et al. [22] reported that serum Mg level of patients with FM were normal. In contrast, Sendur et al. [21] reported that $\mathrm{Mg}$ levels in plasma of patients with FM were lower than control. In another study by Eisinger et al. [12], the erythrocyte $\mathrm{Mg}$ level was slightly lower in patients with FM. Abraham and Flechas [13] also found that Mg deficiency plays a possible role in mechanism of pain in FM. They thought this was related to the role of $\mathrm{Mg}$ in the production of ATP. The present investigation gave no support for the hypothesis that $\mathrm{Mg}$ deficiency in plasma plays a significant role in the development of FM.

Pain is a major symptom of FM. The number of TP is also important [7]. Depression is usually accompanying with FM [35]. We thought that levels of antioxidant vitamin and $\mathrm{Mg}$ might affect these symptoms. We investigated this issue but found no correlation between severity of pain, functional capacity, number of TP, levels of depression, and antioxidant vitamin and $\mathrm{Mg}$ levels. In literature, we encountered no study investigating the correlation between antioxidant vitamins and clinical parameters. The association between serum $\mathrm{Mg}$ level and clinical parameters was investigated only by Sendur et al. [21]. They found no statistically significant association between $\mathrm{Mg}$ levels and clinical parameters (pain, number of TP, functional capacity, disease duration, morning stiffness).

The major limitation of the current study is the limited number of patients who were all women. Future studies should include larger populations and both sexes. Previous studies of FS patients in our country had similar results of age and duration of disease as in the current study [10,21,23].

According to the results of this study, it was asserted that other complex mechanism may play an important role in 
the pathophysiology of FM without plasma antioxidant vitamins and $\mathrm{Mg}$ levels. These findings justify further researches to explore the effect of antioxidant vitamins and $\mathrm{Mg}$ trace element in FM.

\section{Disclosures None}

Open Access This article is distributed under the terms of the Creative Commons Attribution Noncommercial License which permits any noncommercial use, distribution, and reproduction in any medium, provided the original author(s) and source are credited.

\section{References}

1. Ozgocmen S, Ozyurt H, Sogut S, Akyol O (2006) Current concepts in the pathophysiology of fibromyalgia: the potential role oxidative stress and nitric oxide. Rheumatol Int 26:585-597

2. Halliwell B, Guttedridge JM. (eds) (1996) Free radicals, ageing, and disease. In: Free Radicals in Biology and Medicine. Clarendon Press, Oxford, UK, pp 417-506.

3. Valko M, Leibfritz D, Moncol J, Cronin MTD, Mazur M, Telser J (2007) Free radicals and antioxidants in normal physiological functions and human disease. Int J Biochem Cell Biol 39:44-84

4. Akyol O, Ișci N, Temel I, Ozgocmen S, Uz E, Murat M, Buyukberber S (2001) The relationship between plasma and erythrocyte antioxidant enzymes and lipid peroxidation in patients with rheumatoid enzymes and lipid peroxidation in patients with rheumatoid arthritis. Joint Bone Spine 68:311-317

5. Ozgocmen S, Sogut S, Ardicoglu O, Fadillioglu E, Pekkutucu I, Akyol O (2004) Serum nitric oxide, catalase, superoxide dismutase, and malondialdehyde status in patients with ankylosing spondylitis. Rheumatol Int 24:80-83

6. Vecchiet J, Capillone F, Falasca K, Mezzetti A, Pizzigallo E, Bucciarelli T, De Laurentis S, Affaitati G, De Cesare D, Giamberardino MA (2004) Relationship between musculoskeletal symptoms and blood markers of oxidative stres in patients with chronic fatigue syndrome. Neurosci Lett 335:151-154

7. Bennett RM (1997) The fibromyalgia syndrome. In: Kelley WN, Haris ED, Ruddy S, Sledge CB (eds) Textbook of rheumatology. WB Saunders Company, Philadelphia, pp 511-519

8. Mease P (2005) Fibromyalgia syndrome: review of clinical presentation, pathogenesis, outcome measures, and treatment. J Rheumatol Suppl 75:6-21

9. Ozgocmen S (2006) New strategies in evaluation of therapeutic efficacy in fibromyalgia syndrome. Curr Pharm Des 12:67-71

10. Bagiș S, Tamer L, Sahin G, Bilgin R, Guler H, Ercan B, Erdogan C (2005) Free radicals and antioxidants in primary fibromyalgia: an oxidative stress disorder? Rheumatol Int 25:188-190

11. Wolfe F, Ross K, Anderson J, Russell IJ, Hebert L (1995) The prevalence and characteristics of fibromyalgia in the general population. Arthritis Rheum 38:19-28

12. Eisinger J, Plantamura A, Marie PA, Ayavou T (1994) Selenium and magnesium status in fibromyalgia. Magnes Res 7:285-288

13. Abraham GE, Flechas JD (1992) Management of fibromyalgia: rationale for the use of magnesium and malic acid. J Nutr Med 3:49-59

14. Nazıroğlu M, Şimşek M, Kutlu M (2004) Moderate exercise with dietary vitamin $\mathrm{C}$ and $\mathrm{E}$ combination protects streptozotocin- induced oxidative damage to the blood and improves fetal outcomes in pregnant rats. Clin Chem Lab Med 42:511-517

15. Sies H, Stahl W, Sundquist AR (1992) Antioxidant functions of vitamins: vitamins $\mathrm{E}$ and $\mathrm{C}$, B-carotene, and other carotenoids. Ann NY Acad Sci 669:7-20

16. Packer L, Landvik S (1990) Vitamin E in biological systems. In: Emerit I, Packer L, Auclair C (eds) Antioxidants in therapy and preventive medicine. Plenum Pres, New York, pp 93-103

17. McDowell LR (1989) In: McDowell LR (ed) Vitamins in animal nutrition - comparative aspects to human nutrition: vitamin A. Academic, London, pp 10-52

18. McDowell LR (1989) In: McDowell LR (ed) Vitamins in animal nutrition - comparative aspects to human nutrition: vitamin A. Academic, London, pp 93-131

19. Sies H, Stahl W (1995) Vitamins E and C, $\beta$-carotene, and other carotenoids as antioxidants. Am J Clin Nutr 62:1315-1321

20. Romano TJ, Stiller JW (1994) Magnesium deficiency in fibromyalgia syndrome. J Nutr Med 4:165-167

21. Sendur OF, Tastaban E, Turan Y, Ulman C (2008) The relationship between serum trace element levels and clinical parameters in patients with fibromyalgia. Rheumatol Int 28:1117-1121

22. Rosborg I, Hyellen E, Lidbeck J, Nihlgard B, Gerhardsson L (2007) Trace element pattern in patients with fibromyalgia. Sci Total Environ 385(1-3):20-27

23. Akkuș S, Nazıroğlu M, Eriș S, Yalman K, Yılmaz N, Yener M (2009) Levels of lipid peroxidation, nitric oxide, and antioxidant vitamins in plasma of patients with fibromyalgia. Cell Biochem Funct 27:181-185

24. Eisinger J, Gndolfo C, Zakarian H, Ayavou T (1997) Reactive oxygen species, antioxidant status and fibromyalgia. J Musculoskelet Pain 5(4):5-15

25. Wolfe F, Smythe HA, Yunus MB, Bennet RM, Bombardier C, Goldenberg DL, Tugwell P, Campbell SM, Abeles M, Clark P (1990) The American College of Rheumatology 1990 criteria for the classification of fibromyalgia. Arthritis Rheum 33:160 172

26. Huskisson EC (1983) Visual analogue scales. In: Melzac R (ed) Pain measurement and assessment. Raven, New York, pp 33-37

27. Sarmer S, Ergin S, Yavuzer G (2000) The validity and reliability of the Turkish version of the Fibromyalgia Impact Questionnaire. Rheumatol Int 20:9-12

28. Beck AT, Ward CH, Mendelson M, Mock J, Erbaugh J (1961) An inventory for measuring depression. Arch Gen Psychiatry 4:561-571

29. Fassbender HG, Wegner K (1973) Morphologyy and pathogenesis of soft tissue rheumatism. Z Rheumaforsch 32:355-374

30. Lund N, Bengtsson A, Thorborg P (1986) Muscle tissue oxygen pressure in primary fibromyalgia. Scand J Rheumatol 15:165-173

31. Jeschonneck M, Grohmann G, Hein G, Sprott H (2000) Abnormal microcirculation and temperature in skin above tender points in patients with fibromyalgia. Rheumatology 39:917-921

32. Altındag O, Celik H (2006) Total antioxidant capacity and severity of the pain in patients with fibromyalgia. Redox Rep 3:131-135

33. Sendur OF, Turan Y, Tastaban E, Yenisey C, Serter M (2009) Serum antioxidants and nitric oxide levels in fibromyalgia: a controlled study. Rheumatol Int 29:629-633

34. Prescott E, Norregard J, Pedersen LR, Danneskiold SB, Bülow P (1992) Red blood cell magnesium and fibromyalgia. Scand J Rheumatol 94(31):154

35. Wolfe F (1996) The fibromyalgia syndrome: a consensus report on fibromyalgia and disability. Special report. J Rheumatol 23:534-559 